\title{
Radiosurgery for Trigeminal Neuralgia Secondary to Dolichoectatic Vessels: Case Series and Review of Literature
}

\author{
Manjul Tripathi ${ }^{1,2, \odot}$ Sandeep Mohindra ${ }^{1} \quad$ Renu Madan ${ }^{3} \quad$ Chirag K. Ahuja ${ }^{4} \quad$ Aman Batish ${ }^{1}$ \\ Rupinder Kaur ${ }^{1} \quad$ Sushant Dutta ${ }^{1} \quad$ Ninad R. Patil ${ }^{1} \quad$ Vasundhara S. Rangan ${ }^{5}$ Sonikpreet Aulakh ${ }^{6}$
}

\footnotetext{
${ }^{1}$ Department of Neurosurgery, Postgraduate Institute of Medical Education and Research (PGIMER), Chandigarh, India

${ }^{2}$ National Institute of Health Research (NIHR) Global Health Research Group on Neurotrauma, University of Cambridge, Cambridge, United Kingdom

${ }^{3}$ Department of Radiotherapy, Postgraduate Institute of Medical Education and Research (PGIMER), Chandigarh, India

${ }^{4}$ Department of Radiodiagnosis, Postgraduate Institute of Medical Education and Research (PGIMER), Chandigarh, India

${ }^{5}$ Department of Neurosurgery, Nizam Institute of Medical Sciences, Hyderabad, India

${ }^{6}$ Department of Translational Neuro-Oncology, West Virginia

Cancer Institute, Morgantown, United States
}

\author{
Address for correspondence Manjul Tripathi, MCh, Department of \\ Neurosurgery, Postgraduate Institute of Medical Education and Research, \\ Chandigarh 160012, India (e-mail: drmanjultripathi@gmail.com).
}

\begin{abstract}
Keywords

- Gamma Knife radiosurgery

- megadolicobasilar artery

- trigeminal neuralgia

- microvascular decompression
\end{abstract}

Even for seasoned neurosurgeons who have mastered the microvascular decompression (MVD) techniques, trigeminal neuralgia (TGN) secondary to vertebrobasilar dolichoectatic vessels remains a challenge. Often, patient is either medically infirm or unwilling for invasive surgical interventions. Alternative treatment options including Gamma Knife radiosurgery (GKRS) are considered in such a situation with variable success. This study aimed to evaluate the role of GKRS in patients with trigeminal neuralgia with dolichoectatic vessels and severe cross compression. We prospectively managed three male patients of intractable TGN secondary to dolichoectatic vascular compression with single-session GKRS. The cisternal component of the trigeminal nerve was targeted with 90 Gy radiation at $100 \%$ isodose with a single $4-\mathrm{mm}$ collimator. The patients were regularly evaluated on clinical parameters for pain relief (Barrow Neurological Institute (BNI) score), sensory complaints, and outcome. All patients had satisfactory pain control (BNI I-IIIa) at 3 months of interval only to get recurrent pain (BNI IV-V) after 6 months. The treatment was eventually considered a failure after 6-month duration and one patient needed MVD for pain control. Post-GKRS pain control remains inferior in patients with dolichoectasia compared with typical TGN. GKRS should be offered only as a salvage or rescue procedure and should not be used as an alternative treatment of MVD in patient population with dolichoectatic vessels. published online April 13, 2021
DOI https://doi.org/

$10.1055 / \mathrm{s}-0041-1726150$ ISSN 0976-3147.
(C) 2021. Association for Helping Neurosurgical Sick People. This is an open access article published by Thieme under the terms of the Creative Commons Attribution-NonDerivative-NonCommercial-License, permitting copying and reproduction so long as the original work is given appropriate credit. Contents may not be used for commercial purposes, or adapted, remixed, transformed or built upon. (https://creativecommons.org/licenses/by-nc-nd/4.0/). Thieme Medical and Scientific Publishers Pvt. Ltd. A-12, 2nd Floor, Sector 2, Noida-201301 UP, India 


\section{Introduction}

Trigeminal neuralgia (TGN), secondary to vertebrobasilar dolichoectasia, is a challenging surgical disorder. ${ }^{1}$ There are a plethora of drugs and procedures used to treat TGN but none is a panacea. Many clinicians believe that a neurovascular conflict is at the heart of the pathogenesis. Surgical management of TGN involves the physical separation of the nerve and the vascular loop leading to mechanical decompression. Microvascular decompression (MVD) remains the gold-standard treatment. The Gamma Knife radiosurgery (GKRS) is now as an established alternative treatment modality for TGN. ${ }^{2-4}$ The literature confirms better long-term pain control with MVD compared with GKRS. However, many of these patients now consider GKRS as the primary treatment modality when their pain gets medically refractory in view of its better safety and complication profile. ${ }^{1,4}$ This choice is also often motivated by the ability to avoid the hospitalization and recovery associated with the MVD procedure.

Very rarely (2\% cases), a dolichoectatic vessel might be the reason of compression and intractable TGN.${ }^{5,6}$ Statistically, most of these patients are hypertensive male in their sixth decade of life and with predominant left-sided compression. MVD provides satisfactory pain control (96\% at 1 year, $92 \%$ at 3 years, and $86 \%$ at 10 years $)^{6}$ but carries high chance of cranial neuropathy. It includes postoperative trigeminal sensory dysfunction (29-42\%), diplopia (23-24\%), facial paresis (7-10\%), and hearing loss in 4 to $13 \%$ patients. The complications may be permanent in $11 \%$ cases. $^{5-7}$ Surgery is technically difficult too, as the vessels are firm and difficult to decompress ( - Fig. 1A). Occasionally, it becomes impossible to insert a Teflon between the vessel and the nerve $(-$ Fig. 1B), hence other techniques, such as sling procedures, have also been proposed. ${ }^{8,9}$ Seldom, we encounter patients who refuse invasive surgical interventions or want to keep it a secondary procedure, if the primary radiosurgery fails. When secondary to dolichoectasia, the results of GKRS are not as encouraging as for typical TGN. ${ }^{6,10}$ In this article, authors discuss their experience with GKRS for this cohort of patients and evaluates the current role and indications.

\section{Methodology}

Authors described their experience in managing three patients of TGN secondary to dolichoectatic vertebrobasilar complex with primary GKRS. All patients were medically refractory and refused MVD (-Table 1). No patient underwent any prior invasive intervention before GKRS. All patients were initially evaluated on clinicoradiological parameters, and the pain was prospectively evaluated on the Barrow Neurological Institute (BNI) grading ${ }^{3}$ ( Fig. 2). The radiological parameters involved T1, T2, contrast, and constructive interference in steady-state sequences of magnetic resonance imaging (MRI) at 1-mm nonoverlapping continuous imaging. The trigeminal nerve was identified on all the three axes, that is, axial, coronal, and sagittal planes. The distal cisternal component of trigeminal nerve was targeted with a 4-mm single shot (-Fig. 3). The prescription dose was 90 Gray at $100 \%$ isodose. The plan was unanimously approved by a neurosurgeon, radiation oncologist, and medical physicist. The clinical parameters at follow-up ( 3 months, 6 months, and 1 year) were pain control on the BNI grading and sensory complaints in the form of hypoesthesia and numbness. We also evaluated the degree of pain relief, latency interval for pain relief, continued requirement for medication, need for further surgical procedures, development of any new symptoms or signs, and need for and response to additional surgical procedures.

Table 1 The Barrow Neurological Institute grading for pain

\begin{tabular}{|l|l|}
\hline Grade & Pain severity \\
\hline Grade I & No pain, no medication \\
\hline Grade II & Occasional pain, not requiring medication \\
\hline Grade IIla & No pain but continued medication \\
\hline Grade IIIb & $\begin{array}{l}\text { Pain present but adequately controlled on } \\
\text { medication }\end{array}$ \\
\hline Grade IV & $\begin{array}{l}\text { Pain present but not adequately controlled on } \\
\text { medication }\end{array}$ \\
\hline Grade V & Severe pain despite medication \\
\hline
\end{tabular}

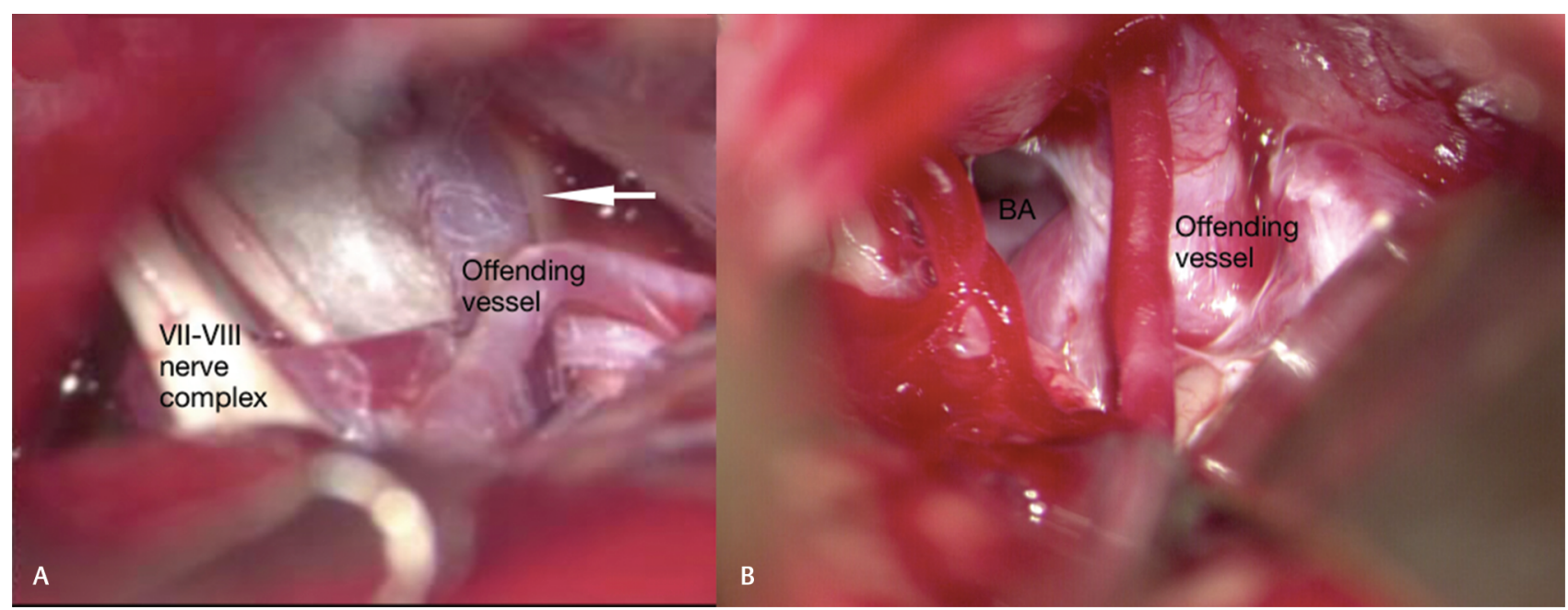

Fig. 1 (A) Dolichoectatic vessel compressing the thinned out trigeminal nerve; (B) dolichoectatic vertebrobasilar complex and enlarged vein compressing the cisternal and root entry zone of trigeminal nerve (arrow suggestive of thinned out right trigeminal nerve). BA, basilar artery. 


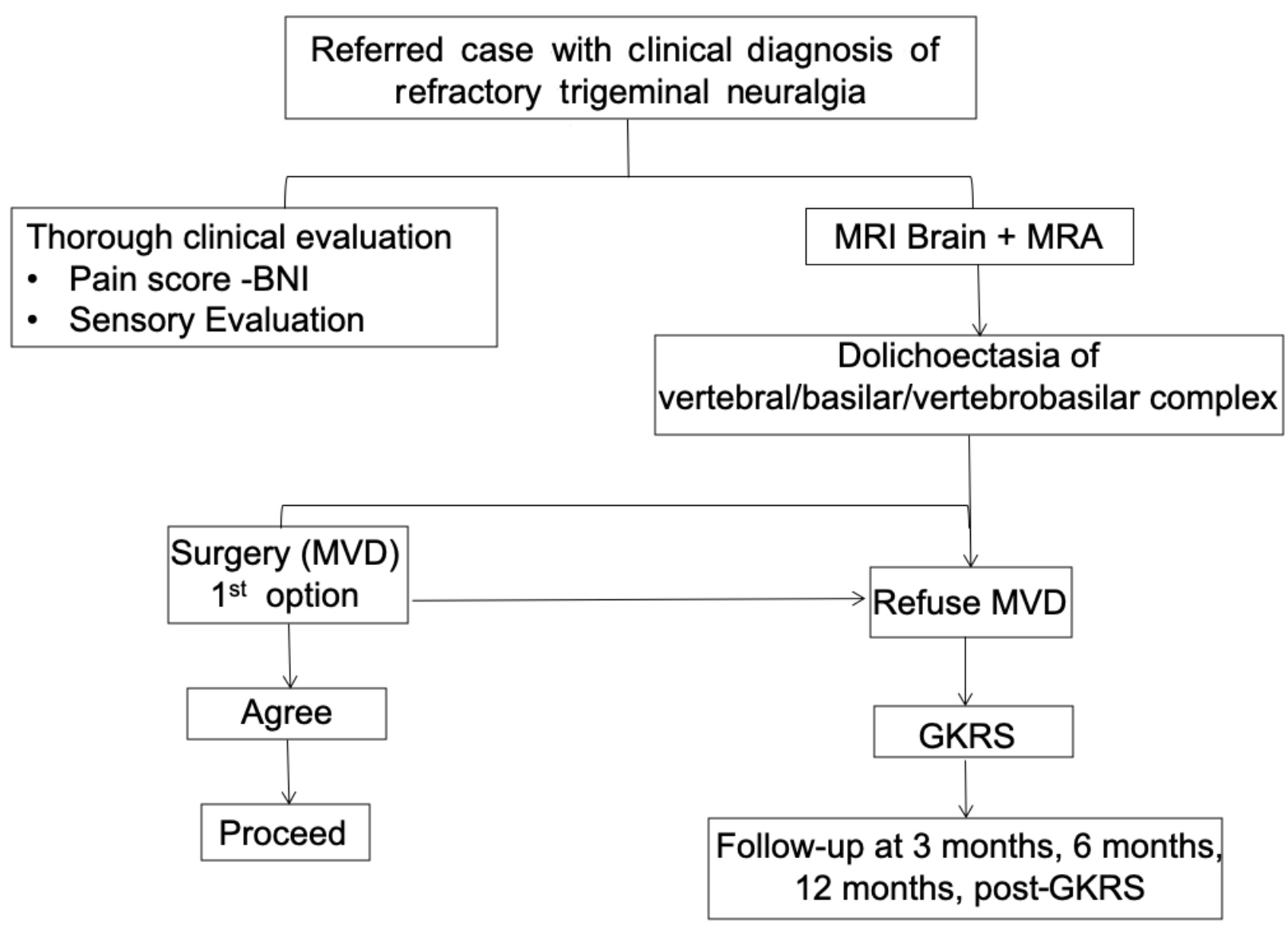

Fig. 2 The algorithm to manage patients with intractable trigeminal neuralgia secondary to dolichoectatic vessels. BNI, Barrow Neurological Institute grading; GKRS, Gamma Knife radiosurgery; MRA, magnetic resonance angiography; MRI, magnetic resonance imaging; MVD, microvascular decompression.

\section{Results}

All three patients were male of 44,52 , and 70 years, respectively, with BNI V at presentation. The follow-up period is 13 , 18 , and 12 moths, respectively. All patients reported satisfactory pain control at 3 months follow up (BNI III) but suffered recurrent pain at 6 months interval. All three patients developed some hypoesthesia which was non bothersome and improved by 6 months follow up. One patient received redo GKRS after 11 months of the primary GKRS and enjoyed few more months of pain relief with later failure. This patient later needed MVD and is now pain free with no hemifacial spasm at present. Intraoperatively, the arachnoid was thick-

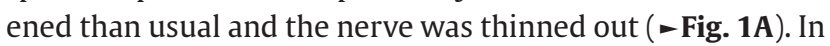
view of the vessel tortuosity and increased turgor ( - Fig. 1B), one needs to insert more amount of Teflon than usual to avoid the recurrence of the disease. Remaining two patients are on added medication ( $\mathbf{- T a b l e ~} \mathbf{2}$ ).

\section{Discussion}

A dolichoectasia is classically defined as a vessel diameter of at least $4.5 \mathrm{~mm} .{ }^{11}$ This leads to compression and/or distortion of ipsilateral trigeminal nerve or brain stem. A dolichoectatic vertebrobasilar complex poses unique challenge when presents with cranial neuropathy. The clinical presentation includes features of compression of cranial nerves, obstructive hydrocephalus, and intracranial ischemic or hemorrhagic events. ${ }^{12}$ In extreme cases, there might be features of brain-stem compression including long-tract signs. The rarity of this situation can be understood by the fact that even in the famed series of Peter Jannetta, there was not even a single case of dolichoectasia. The mechanical distortion in dolichoectasia is axiomatic warranting physical separation of vessel from the nerve. However, the MVD remains technically challenging. There are high chances of postoperative cranial neuropathy, which remains permanent in $11 \%$ of cases. ${ }^{6}$ The spectrum of the surgical management ranged from rhizolysis, GKRS, MVD, and radiofrequency ablation to foramen magnum decompression. ${ }^{13}$

\section{Gamma Knife Radiosurgery for Trigeminal Neuralgia Secondary to Dolichoectasia}

There are certain nuances in radiosurgical management of this disorder. In most of the cases, the dolichoectasia distorts the brain stem to an extent that the pathological side has a longer length of the cisternal component of the trigeminal nerve. This gives a certain strategic advantage, as the trigeminal nerve can be safely targeted avoiding any 
radiation spillage to the brain stem ( - Fig. 3B). Seldom, a shot, even as small as $4 \mathrm{~mm}$, may need to be modified with beam blocking and dynamic shipping to safeguard the brain stem and cochlea. Rarely, the nerve is so much indented that radiological visualization of the trigeminal nerve becomes practically impossible. In those cases, the only possible target remains either at the root entry zone or Meckel's cave (-Fig. 3D).

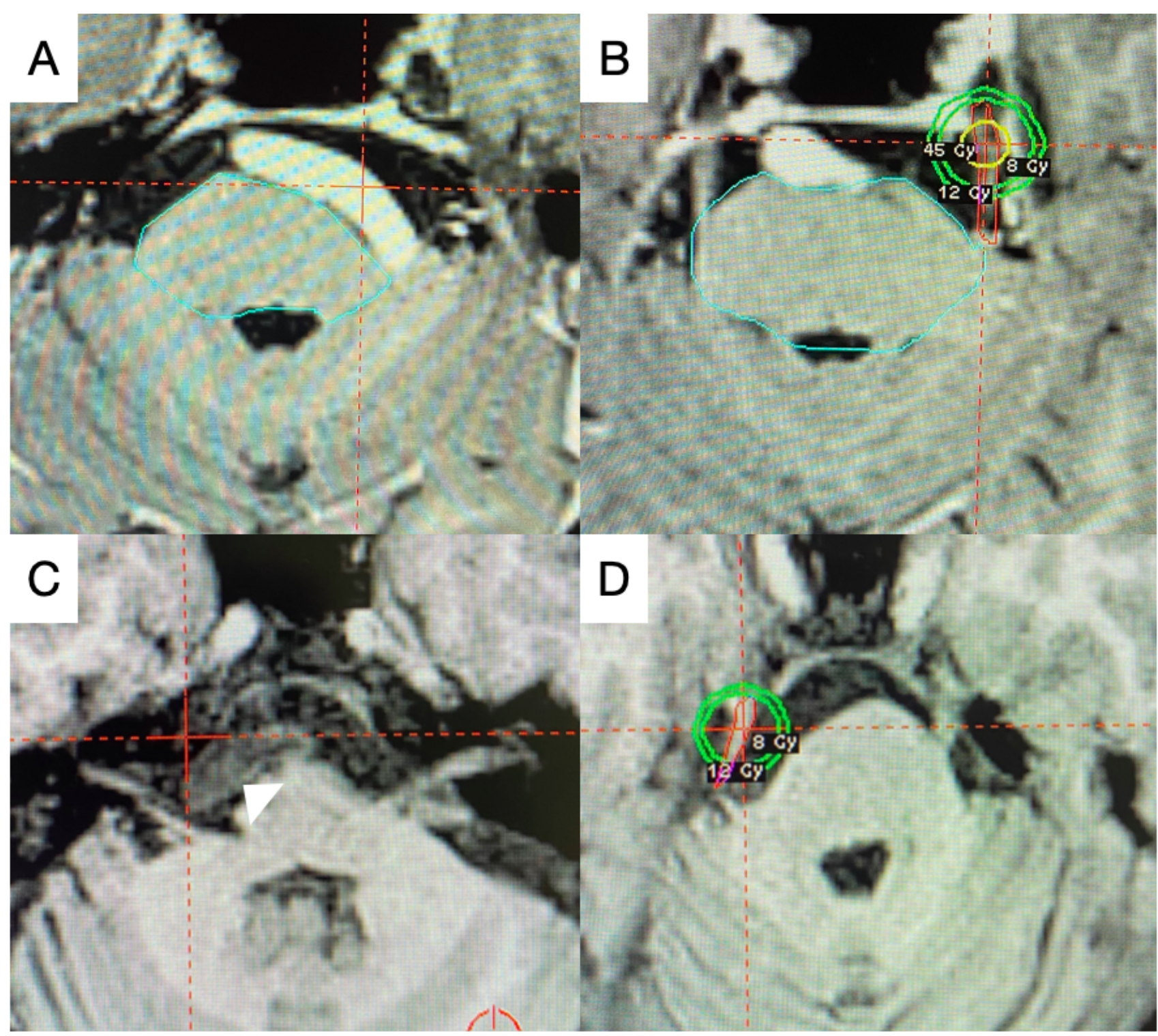

Fig. 3 (A) The dolichoectatic vessel on the left side of the brain stem; (B) the radio surgical targeting of distal cisternal component of trigeminal nerve (patient A); (C) Right sided dolichoectatic vessel (arrowhead, patient B); and (D) radiosurgical targeting of the distorted right trigeminal nerve (patient B).

Table 2 The demographic and clinical characteristics of the patients treated with GKRS for trigeminal neuralgia secondary to dolichoectasia

\begin{tabular}{|c|c|c|c|c|c|c|c|c|c|c|c|}
\hline \multirow[t]{2}{*}{ Patient } & \multirow[t]{2}{*}{ Age (y) } & \multirow[t]{2}{*}{ Sex } & \multirow[t]{2}{*}{ TGN for } & \multirow{2}{*}{$\begin{array}{l}\text { Involved } \\
\text { territory }\end{array}$} & \multirow{2}{*}{$\begin{array}{l}\text { Associated } \\
\text { complaints }\end{array}$} & \multirow[t]{2}{*}{ GKRS } & \multirow{2}{*}{$\begin{array}{l}\text { Pre-GKRS } \\
\text { BNI }\end{array}$} & \multicolumn{3}{|c|}{ Post-GKRS BNI } & \multirow[t]{2}{*}{ Follow-up (mo) } \\
\hline & & & & & & & & $3 m$ & $6 \mathrm{~m}$ & $1 y$ & \\
\hline A & 53 & $M$ & $1 \mathrm{y}$ & $\begin{array}{l}\mathrm{V} 2>\mathrm{V} 3 \\
(\mathrm{~L})\end{array}$ & HFS & $2 x$ & V & Illa & V & III & 18 \\
\hline B & 44 & $M$ & $6 \mathrm{mo}$ & $\begin{array}{l}\text { V2 > V3 } \\
(R)\end{array}$ & $\begin{array}{l}\text { Renal trans- } \\
\text { plant patient }\end{array}$ & $1 \mathrm{x}$ & V & IIIb & IV & IV & 13 \\
\hline C & 70 & $M$ & $3 y$ & $\begin{array}{l}\text { V3 > V2 } \\
\text { (L) }\end{array}$ & $\begin{array}{l}\text { CAD } \\
\text { (post-CABG) }\end{array}$ & $1 \mathrm{x}$ & V & IIIb & V & V & 12 \\
\hline
\end{tabular}

Abbreviations: BNI, Barrow Neurological Institute scoring; CABG, coronary artery bypass graft; CAD, coronary artery disease; GKRS, Gamma Knife radiosurgery; HFS, hemifacial spasm; L, left; M, male; R, right; TGN, trigeminal neuralgia. 


\section{Comparative Pain Relief}

Compared with typical TGN patient population, this cohort has lesser chances of long-term pain control, and the extent of pain relief after GKRS. There are high chances of pain recurrence and the need for additional procedures after primary GKRS. Despite initial pain relief, most of the patients experience the recurrence of pain within 12 months of primary treatment. Park et al published their series of 30 patients with dolichoectasia treated with GKRS with the probability of maintaining pain relief of 53,38 , and $10 \%$ at 1,2 , and 5 years respectively. Overall, $10 \%$ patient suffered facial sensory dysfunction and $70 \%$ patients underwent an additional surgical procedure. ${ }^{6}$ Tuleasca et al in their experience of 29 patients of dolichoectasia reported $93.1,79.3$, and $75.7 \%$ actuarial probability of remaining pain free without medication at 6 months, 1 and 2 years, respectively. The sensory complications were reported at $4.3 \%$ at 6 months and $13 \%$ at 1 year, which remained stable until 13 years of posttreatment. Sensory dysfunction is a known possible complication. ${ }^{3}$ Park et al reported $20 \%$ sensory deficit at 2 to 4 month of post-GKRS. However no patient developed corneal sensory loss, trigeminal motor neuropathy, or any other cranial neuropathy. ${ }^{6}$ The results with GKRS were not encouraging. Most of these patients start enjoying a pain-free period (BNI IIII), after an interval of approximately 6 to 12 weeks, but invariably, all have a recurrence of pain by 6 months of the treatment. In the event of the pain recurrence, the suggested strategy is to offer MVD or irradiate the nerve at a point away from the primary target by few millimeters with a relatively lesser dose of 70 to 80 Gray.

\section{What Is the Current Standing of Gamma Knife Radiosurgery in The Management of This Disorder?}

The management of trigeminal neuralgia aims at efficient and long-lasting pain control to improve the patient's quality of life. ${ }^{14}$ The options need to be individually weighed for their safety, efficacy, complication, feasibility profile, and overall patient's expectations and satisfaction. I suggest that the GKRS should only be considered as a salvage or rescue procedure for pain control and in elderly patients with dolichoectasia. Young patients with dolichoectasia should be primarily managed only with MVD. The published literatures echo in this opinion. ${ }^{3,6}$ There are convincing results of durable pain control in typical trigeminal neuralgia with different treatment modalities (viz., glycerol rhizotomy, radiofrequency ablation, GKRS, and MVD) but the same lacks when the offending vessel is dolichoectatic. Till literature gets a robust evidence, MVD should be considered the gold standard and GKRS as a secondary option. Clinicians should explain the different treatment modalities with their attributes and help the patient in choosing the treatment suitable for them.

\section{Conclusion}

The deterrents against radiosurgery for TGN secondary to dolichoectasia are poor pain control, longer latency period, high chances of recurrence, and need for additional procedures. An advantage of GKRS is a day-care treatment and much favorable morbidity and mortality profile, as there is negligible chance of cranial neuropathy. GKRS should only be proposed to the patients who deny surgical intervention or who are not suitable candidates for surgery. It definitely remains an alternative option in patients with extremes of age or severe comorbidities to buy some time. However, its role as a definitive treatment is questionable in this particular patient population.

\section{Funding}

None.

\section{Conflict of Interest}

None declared.

\section{Acknowledgment}

The authors would like to acknowledge the guidance of late Professor Kanchan Kumar Mukherjee for his vision and guidance in management of these cases.

\section{References}

1 Tripathi M. Trigeminal neuralgia: an orphan with many fathers. Neurol India 2019;67(2):414-416

2 Deora $\mathrm{H}$, Tripathi $\mathrm{M}$, Modi $\mathrm{M}$, et al. Letter to the editor. Microsurgical rhizotomy as treatment for trigeminal neuralgia in patients with multiple sclerosis: turnpike or dirt road? J Neurosurg 2018;130(5):1-4

3 Tuleasca C, Régis J, Sahgal A, et al. Stereotactic radiosurgery for trigeminal neuralgia: a systematic review. J Neurosurg 2018;130(3):733-757

4 Tripathi M, Batish A. Letter to the Editor. Cafeteria approach to management of trigeminal neuralgia: stereotactic radiosurgery as a preferred option. J Neurosurg 2018;130(3):1-2

5 Linskey ME, Jho HD, Jannetta PJ. Microvascular decompression for trigeminal neuralgia caused by vertebrobasilar compression. J Neurosurg 1994;81(1):1-9

6 Park K-J, Kondziolka D, Kano H, et al. Outcomes of Gamma Knife surgery for trigeminal neuralgia secondary to vertebrobasilar ectasia. J Neurosurg 2012;116(1):73-81

7 Miyazaki S, Fukushima T, Tamagawa T, Morita A. [Trigeminal neuralgia due to compression of the trigeminal root by a basilar artery trunk. Report of 45 cases] (in Japanese). Neurol Med Chir (Tokyo) 1987;27(8):742-748

8 Kraemer JL, Pereira Filho Ade, David Gd, Faria MdeB. Vertebrobasilar dolichoectasia as a cause of trigeminal neuralgia: the role of microvascular decompression. Case report. Arq Neuropsiquiatr 2006;64(1):128-131

9 Sindou M, Leston JM, Decullier E, Chapuis F. Microvascular decompression for trigeminal neuralgia: the importance of a noncompressive technique-Kaplan-Meier analysis in a consecutive series of 330 patients. Neurosurgery 2008;63(4,suppl 2: 341-350, discussion 350-351 
10 Tuleasca C, Carron R, Resseguier N, et al. Trigeminal neuralgia related to megadolichobasilar artery compression: a prospective series of twenty-nine patients treated with gamma knife surgery, with more than one year of follow-up. Stereotact Funct Neurosurg 2014;92(3):170-177

11 Smoker WR, Corbett JJ, Gentry LR, Keyes WD, Price MJ, McKusker S. High-resolution computed tomography of the basilar artery: 2. Vertebrobasilar dolichoectasia: clinical-pathologic correlation and review. AJNR Am J Neuroradiol 1986;7(1):61-72
12 Passero SG, Rossi S. Natural history of vertebrobasilar dolichoectasia. Neurology 2008;70(1):66-72

13 Goel A, Shah A. Trigeminal neuralgia in the presence of ectatic basilar artery and basilar invagination: treatment by foramen magnum decompression. J Neurosurg 2009;111(6):1220-1222

14 Tripathi M, Sadashiva N, Gupta A, et al. Please spare my teeth! Dental procedures and trigeminal neuralgia. Surg Neurol Int. $2020 ; 11: 455$ 